


\section{LEXICOGRAPHI GRAECI \\ VOL. I \\ SVIDAE LEXICON \\ $A-\Omega \cdot$ INDEX}

EDIDIT

ADA ADLER

K · G · SAUR MÜNCHEN · LEIPZIG 


\title{
SVIDAE LEXICON
}

\author{
EDIDIT \\ ADA ADLER \\ PARS IV \\ $\Pi-\Psi$ \\ EDITIO STEREOTYPA EDITIONIS \\ PRIMAE (MCMXXXV)
}

K · G • SAUR MÜNCHEN • LEIPZIG 2001 
Die Deutsche Bibliothek - CIP-Einheitsaufnahme

Lexicographi Graeci. -

Ed. stereotypa. - München : Leipzig : Saur

(Sammlung wissenschaftlicher Commentare)

Vol. 1. Suidae lexicon : A - O, Index / ed. Ada Adler Ps. 4. P - Ps. -

Ed. stereotypa ed. 1. (1935), 3. Nachdr.. - 2001 ISBN 3-598-74236-3

(C) 2001 by K. G. Saur Verlag GmbH, München und Leipzig Printed in Germany

Alle Rechte vorbehalten. All Rights Strictly Reserved. Jede Art der Vervielfältigung ohne Erlaubnis des Verlages ist unzulässig. Gesarntherstellung: Strauss Offsetdruck, Mörlenbach 